\title{
The relationship between parenting stress and parent-child interaction with health outcomes in the youngest patients with type 1 diabetes ( $0-7$ years)
}

\author{
Anke M. Nieuwesteeg ${ }^{1} \cdot$ Esther E. Hartman $^{1} \cdot$ Henk-Jan Aanstoot ${ }^{2}$. \\ Hedwig J. A. van Bakel ${ }^{3}$. Wilco H. M. Emons ${ }^{1,4}$ - Edgar van Mil ${ }^{5}$. Frans Pouwer ${ }^{1}$
}

Received: 14 February 2015 /Revised: 23 August 2015 / Accepted: 31 August 2015 /Published online: 5 October 2015

(C) The Author(s) 2015. This article is published with open access at Springerlink.com

\begin{abstract}
To test whether parenting stress and the quality of parent-child interaction were associated with glycemic control and quality of life (QoL) in young children ( $0-7$ years) with type 1 diabetes (T1DM), we videotaped 77 families with a young child with T1DM during mealtime (including glucose monitoring and insulin administration). Parent-child interactions were scored with a specifically designed instrument. Questionnaires assessed general and disease-related parenting stress and (diabetes-specific (DS)) QoL. $\mathrm{HbA}_{1 \mathrm{c}}$ (glycemic control) was extracted from the medical records. Both general and disease-related parenting stress were associated with a lower (DS)QoL (r ranged from -0.39 to $-0.70, p<0.05$ ), but not with $\mathrm{HbA}_{1 \mathrm{c}}$ levels. Furthermore, with regard to the parentchild interaction, emotional involvement of parents $(r=0.23$, $p<0.05)$ and expressed discomfort of the child $(r=0.23$, $p<0.05$ ) were related to suboptimal $\mathrm{HbA}_{1 \mathrm{c}}$ levels. There was no clear pattern in the correlations between parent-child interaction and (DS)QoL.
\end{abstract}

Communicated by Jaan Toelen

Esther E. Hartman

e.e.hartman@tilburguniversity.edu

Anke M. Nieuwesteeg

a.m.nieuwesteeg@tilburguniversity.edu

Henk-Jan Aanstoot

h.j.aanstoot@diabeter.nl

Hedwig J. A. van Bakel

h.j.a.vanbakel@tilburguniversity.edu

Wilco H. M. Emons

w.h.m.emons@tilburguniversity.edu

Edgar van Mil

e.milvan@jbz.nl
Conclusion: The results support the notion that diabetes does not only affect the child with T1DM: T1DM is a family disease, as parenting factors (like stress and parent-child interactions) are associated with important child outcomes. Therefore, it is important for health-care providers to not only focus on the child with T1DM, but also on the family system.

\section{What is Known:}

- The incidence of type 1 diabetes is rising, especially in the youngest age group.

- Research examining the association between parenting factors (like stress and interaction with the child) and child outcomes (like glycemic control and quality of life) in this young patient group is scarce.

\section{What is New:}

- Higher levels of parental emotional involvement and more discomfort during disease-specific situations are both related with a less optimal glycemic control in young children with type 1 diabetes.

- Higher levels of both general and disease-related parenting stress are associated with a lower general and diabetes-specific quality of life of young children with type 1 diabetes.

Frans Pouwer

f.pouwer@tilburguniversity.edu

1 Center of Research on Psychology in Somatic diseases (CoRPS), Department of Medical and Clinical Psychology, Tilburg University, Tilburg, The Netherlands

2 Diabeter, 3011 TG Rotterdam, The Netherlands

3 Department of TRANZO, Scientific Center for Care and Welfare, Tilburg University, Tilburg, The Netherlands

4 Department of Methodology and Statistics, Tilburg University, PO Box 90153, 5000 LE Tilburg, The Netherlands

5 Kidz\&Ko, Jeroen Bosch Hospital, ‘s Hertogenbosch, The Netherlands 
Keywords Type 1 diabetes mellitus · Parent-child interaction $\cdot$ Behavior $\cdot$ Children $\cdot$ Parents

Abbreviations
$\begin{array}{ll}\text { DSQoL } & \text { Diabetes-specific quality of life } \\ \mathrm{HbA}_{1 \mathrm{c}} & \begin{array}{l}\text { Hemoglobin } \mathrm{A}_{1 \mathrm{c}} \text { or glycosylated hemoglobin A } \\ \text { protein }\end{array} \\ \text { QoL } & \text { Quality of life } \\ \text { T1DM } & \text { Type 1 diabetes mellitus }\end{array}$

\section{Introduction}

Nowadays, the number of children being diagnosed with T1DM is growing, with an overall annual increase of almost $4 \%$ [35]. This number is particularly growing in the youngest age group $[3,35,50]$. In children with T1DM, achieving an optimal $\mathrm{HbA}_{1 \mathrm{c}}$ level ( $\leq 58 \mathrm{mmol} / \mathrm{mol}$ or $7.5 \%$ [40]) is an important treatment goal. Adequate glycemic control helps to avoid or delay the onset of long-term micro- and macrovascular complications, such as neuropathy, retinopathy, nephropathy and cardiovascular diseases [46]. In addition to these long-term consequences, suboptimal glycemic control is also associated with short-term consequences like a negative effect on school performances $[9,38]$ and child behavior problems $[25,28]$. Despite all efforts, more than half of the children with T1DM still do not reach this optimal $\mathrm{HbA}_{1 \mathrm{c}}$ level [17, 41]. Having T1DM can also have an adverse effect on children's quality of life (QoL) [49]; therefore, health-care providers not only focus on reaching an optimal $\mathrm{HbA}_{1 \mathrm{c}}$ level, but also on maintaining or enhancing a good $\mathrm{QoL}$ in children with T1DM [13]. The literature on QoL in children with T1DM is contradictory as some studies report an obvious impairment in QoL in children with T1DM compared to healthy peers (e.g. [23, 49]), whereas others report a similar level of QoL compared to healthy peers or that children with T1DM even show adaptive outcomes (e.g. [14, 31]). A recent systematic review concluded that the differences in QoL between children with T1DM and healthy peers were, on average, only minimal, although diabetes-specific (DS)QoL problems (e.g. worries, impact on daily functioning) were certainly present [32].

When young children are diagnosed with T1DM, parents have complete responsibility for the daily diabetes management (assessing blood glucose levels, administering insulin, regulating food intake and guarding these parameters in conjunction with the level of physical activity) of their child [10, 42]. Because of these many proceedings, having to think constantly about the correct amount of insulin/carbohydrates, and adjustments during the day without help from daycare or school, parents might consider this as having an 'extra job'. Therefore, it is not surprising that many parents of young children with T1DM report increased levels of parenting stress
[57] and difficulties in parent-child interactions [61]. These parenting factors (parenting stress and parent-child interaction) are strongly linked to parent, child and contextual characteristics [34, 58], like the Process Model of Belsky states [4]. As parent, child and contextual factors are linked to diabetes outcomes [53, 55, 57], parenting stress and parent-child interaction may also be related to the $\mathrm{HbA}_{1 \mathrm{c}}$ level and QoL of the child.

A recent review [8] has described that higher levels of parenting stress were associated with suboptimal $\mathrm{HbA}_{1 \mathrm{c}}$ levels in school-aged children and adolescents (age range 717 years). From the same review, it appeared that in younger children (aged 0-11 years), parenting stress was not or even negatively associated with $\mathrm{HbA}_{1 \mathrm{c}}$ levels, indicating that higher levels of stress were related to more optimal $\mathrm{HbA}_{1 \mathrm{c}}$ levels [8]. This discrepancy in findings between parenting stress and $\mathrm{HbA}_{1 \mathrm{c}}$ levels in parents of school-aged children and adolescents versus parents of young children could be due to the fact that parents of older children have a shared responsibility, while parents of younger children have a full responsibility for the care of their children with T1DM. Increased levels of parenting stress could indicate higher levels of involvement in the diabetes regimen and, therefore, more optimal $\mathrm{HbA}_{1 \mathrm{c}}$ levels in young children [8]. The level of parenting stress has not been associated with child QoL often, as the same review [8] only found one study that associated higher levels of parenting stress with a lower child QoL. This study, however, included only children between 12 and 17 years of age [60]. It is important to gain more knowledge about the associations between parenting factors and child outcomes, as parenting stress might be beneficial for $\mathrm{HbA}_{1 \mathrm{c}}$ levels in young children, but not for child QoL [8]. Therefore, knowledge about the association between parenting stress and child QoL in young children with T1DM is insufficient.

Only a few studies have investigated the quality of parentchild interaction in children with T1DM, showing that, particularly, parental over-involvement, parental restrictiveness, parental hostility, conflicts and negative communication are significantly associated with suboptimal $\mathrm{HbA}_{1 \mathrm{c}}$ levels (e.g. [2, 6, $10,22,26,27,59])$ and a lower reported QoL (e.g. [24, 56]). In contrast, positive maternal communication, positive reinforcement, emotional support, parental warmth and caring behavior appeared to be significantly associated with more optimal $\mathrm{HbA}_{1 \mathrm{c}}$ levels (e.g. [22, 27, 62]) and a better reported QoL (e.g. $[18,22])$ of children and adolescents with T1DM. However, the aforementioned studies mainly focused on older children (aged 8-20 years) [2, 6, 18, 22, 24, 26, 27, 56, 62] or used rather diverse age groups (aged 4-14) [10,59], and therefore, research in exclusively (very) young children is limited. We have only found one study that directly observed parentchild interaction in younger children (aged 2-8 years) [37]. This study showed that ineffective parenting during mealtime (i.e., coaxes, interrupted commands and physical prompts) 
was significantly related to suboptimal $\mathrm{HbA}_{1 \mathrm{c}}$ levels [37]. Currently, research on the parent-child interaction in younger children including also QoL as an outcome factor is lacking.

Research examining the associations among parenting stress, parent-child interaction and child outcomes in young children with T1DM is scarce and urgently needed. More insight in this area may contribute to the development of new, effective interventions. Therefore, the present study was conducted to test whether, and how, parenting stress and the quality of parent-child interaction were related to the $\mathrm{HbA}_{1 \mathrm{c}}$ level and QoL in young children ( $0-7$ years) with T1DM.

\section{Methods}

\section{Patients and procedure}

Children (aged 0-7 years) diagnosed with T1DM more than 6 months and their parents were recruited from 15 hospitals/ institutions in the middle and southern part of the Netherlands (including Kidz\&Ko, a partnership between seven pediatric diabetes clinics, and Diabeter, a national center for pediatric and adolescent diabetes care and research). Parents who lacked basic proficiency in Dutch and children with an Autism Spectrum Disorder, Down syndrome and/or other mental disabilities $(n=17)$ were excluded. Of the 121 eligible families, 77 families (64\%) agreed to participate. After receiving written informed consent, the mealtime situation (including glucose monitoring and insulin administration) was videotaped during a home visit (for a detailed description of the procedure of the home visits, see Nieuwesteeg et al. [33]). The home visits took place between August 2010 and July 2011. Furthermore, both parents were asked to complete a questionnaire assessing (socio)demographic and clinical variables, general and disease-specific parenting stress and generic and diabetes-specific (DS) child QoL. In the present study, only scores of the questionnaires of the parent who was videotaped during the interaction were used. The study was approved by the Medical Ethical Review board of St. Elisabeth Hospital Tilburg (date: 25-05-2010).

\section{Measures}

\section{(Socio)demographic and clinical variables}

The first part of the questionnaire included items involving (socio)demographic characteristics (i.e. gender and age of the child, marital status and educational levels of both parents) and clinical characteristics (i.e. treatment regimen, frequency of blood glucose monitoring (average number of assessments/ day) and years since diagnosis).

\section{Metabolic control}

Glycemic control $\left(\mathrm{HbA}_{1 \mathrm{c}}\right.$ level) was determined at the hospital where the child was treated for T1DM and extracted from the medical records of the children, after receiving written consent from the parents. In clinical care, the $\mathrm{HbA}_{1 \mathrm{c}}$ level is generally measured once every $2-3$ months and gives an impression of the average blood glucose level over a 6- to 12week period. Using the patient's charts, we included the $\mathrm{HbA}_{1 \mathrm{c}}$ level measured closest to the home visit (maximum of 3 months before or after the home visit).

\section{Parent-child interaction}

To assess the quality of parent-child interaction, the mealtime situation (including glucose monitoring and insulin administration) was videotaped in all participating families during a home visit. The videotapes were scored by an observer (AN) with the qualitative OKI-DO observation instrument, which is specifically developed for children with T1DM, to assess the quality of parent-child interaction during diabetes-specific situations [33]. This observation instrument comprises ten domains, including four parent domains (emotional involvement, limit setting, respect for autonomy and quality of instruction ), four child domains ( negative behavior, avoidance, cooperative behavior and child's response to injection) and two family domains (emphasis on diabetes and mealtime structure ). The parent-child dyad will receive a score (1-5) on each domain, in which higher scores reflect more of the behavior (e.g. a high score on 'emotional involvement' means the parent is highly emotional involved, and a high score on 'negative behavior' means the child shows a lot of negative behavior). An example of the rating scale respect for autonomy can be rated varying from score 1 :

'The caregiver receives this score if he/she fully determines what should happen without explaining anything to the child and with a visible lack of respect for the autonomy. For example, the caregiver just takes the finger of the child to check the glucose, (harshly) 'pulls' the child in the correct position to operate the insulin pump or determines (without consulting or warning the child) where and when the insulin injection takes place, the caregiver fully determines what and how much the child eats. If the child is (rather) independent in managing his/ her diabetes, the caregiver receives this score if he/she repeatedly interferes when the child is managing his/her diabetes, while it is clear from the observation that the child can perform everything on its own'.

To score 5: 'The caregiver receives this score if he/she praises initiatives of the child and encourages the child to make decisions on his own regarding his/her diabetes. The child may, for example, read the glucose meter, operate the insulin pump or determine where and when the insulin injection takes place (the caregiver could of course check the things 
his/her child does, but is herein not at all intrusive). Everything is determined in consultation with the child and the child is treated with respect.'

Research shows encouraging indications for the usability, reliability and preliminary validity of the OKI-DO instrument to assess parent-child interaction in young children with T1DM during mealtime (including glucose monitoring and insulin administration) [33].

\section{General parenting stress}

General parenting stress was assessed with the short Dutch version of the Parenting Stress Index [1, 12]. This is a 17item self-report measure, in which parents report how much they agree on the propositions about stress in the parent-child system. The items are rated from 1 (strongly disagree) to score 4 (strongly agree). All items were summed to get a total score $(\alpha=0.92)$. Higher scores reflect more general parenting stress. The 17-item version has shown good reliability [48].

\section{Disease-related parenting stress}

Disease-related parenting stress was assessed with a validated, 42-item self-report measure, the Pediatric Inventory for Parents (PIP) [44, 54]. Parents are asked to describe both the frequency and difficulty of experienced disease-related parenting stress across four domains: communication (for example: with the medical team, partner, child), emotional distress (for example: quality of sleep, effect on mood), medical care (for example: treatment demands) and role functioning (for example: being able to go to work). All items are scored on a 5-point Likert scale on both frequency and difficulty. The scale scores were summed to get a total frequency $(\alpha=0.93)$ and total difficulty score $(\alpha=0.93)$. Higher scores reflect more frequency and difficulty in disease-related parenting stress. Adequate internal consistency and construct validity of the original version of the PIP have been reported [44].

\section{QoL of the children}

Generic QoL was measured with the TNO-AZL Preschool Quality Of Life questionnaire or TAPQOL [15] in children in the age of 1 through 5 years of age and the TNO-AZL Child Quality Of Life questionnaire or TACQOL [52] in children of 6 and 7 years of age. These multidimensional questionnaires are proxy measures, as they assess the parent's perceptions of health-related QoL in (preschool) children. The TAPQOL includes 43 items constituting 12 scales covering aspects of QoL: seven health-related scales: stomach problems, skin problems, lung problems, sleeping problems, appetite, motor functioning and communication (these seven scales were summed and then averaged (health-related QoL), $\alpha=$ 0.80 ) and five psychosocial-related scales: liveliness, positive mood, problem behavior, anxiety and social functioning (these five scales were summed and then averaged (psychosocial QoL), $\alpha=0.75$ ). The TACQOL includes 63 items constituting seven scales covering aspects of QoL: five healthrelated scales: pain and symptoms, motor function, autonomy, cognitive functioning and interaction with parents and peers (these five scales were summed and then averaged (healthrelated QoL), $\alpha=0.94)$, and two psychosocial-related scales: experience of positive and negative emotions (the two scales were summed and then averaged (psychosocial QoL), $\alpha=$ 0.84 ). In both questionnaires, the parent indicates to what extent specific problems of the health-related functioning scales occurred in the past few weeks, with three response categories: 'never', 'sometimes' and 'often'. If a problem occurs, the parents are asked how the child is feeling: '(very) good', 'not so good', 'pretty bad', and 'bad'. For each item, the two answers are combined into a single item score ranging from 0 to 4 ('never' 4 and 'sometimes' or 'often' combined with '(very) good' 3 , 'not so good' 2 , 'pretty bad' 1 , and 'bad' $0)$. With the psychosocial-related scales, the parents indicate on a Likert scale whether a certain emotion in their child has appeared in the last few weeks (never, sometimes, often). Item scores for the psychosocial-related scales run from 0 to 2 . All TAPQOL and TACQOL scales are linearly transformed to 0 100 scales; higher scores will correspond to a better QoL. Research showed that the TAPQOL and the TACQOL are reliable and valid questionnaires $[16,19]$.

Diabetes-specific QoL (DSQoL) was measured with a child self-report questionnaire (Smiley Faces) for young children composed by the Hvidøre Study Group [21]. This questionnaire has been modified in a proxy-report form with permission of the authors so that the parents can complete the questionnaire for their child. The questionnaire comprises 19 items about feelings of the child in relation with his or her diabetes (for example, items about administering insulin, health, leisure time, and school/nursery/daycare). The items are rated on a 5-point Likert scale. Scores are (re)coded so that a higher score corresponds to a better QoL. All items were summed to get a total diabetes-specific QoL score $(\alpha=0.86)$. The originally child self-report questionnaire showed good reliability and validity [21].

\section{Statistical analyses}

Statistical analyses were conducted using the Statistical Package for the Social Sciences (SPSS, version 19). Frequencies and descriptive statistics were used to present the (socio)demographic and diabetes-related characteristics of the participating families. Pearson's correlation coefficients were calculated to examine the strength of the relationships between parenting stress and the parent-child interaction with $\mathrm{HbA}_{1 \mathrm{c}}$ levels and (DS)QoL. Because different QoL questionnaires were used for children aged $0-5$ and $6-7$, we have 
examined the Pearson's correlations for these questionnaires (generic and DS QoL) separately. The results of the correlations were considered statistically significant when $p \leq 0.05$. Furthermore, the effect sizes were examined. According to Cohen, $r$ of $0.10,0.30$ and 0.50 are considered as small, medium and large effects, respectively [7]. We did not perform a power analysis.

\section{Results}

\section{Sociodemographic and clinical data}

Table 1 summarizes the characteristics of participating parents and children. Among the participating children, there were 41 boys $(53 \%)$. The children with T1DM had a mean age of 5 years ( $\mathrm{SD}=1.5$, range: $2-7$ years). Most children ( $82 \%)$ received pump therapy. On average, parents monitored their child's blood glucose 6 times a day (range: 2-20). The mean $\mathrm{HbA}_{1 \mathrm{c}}$ level of the children, measured closest to the home visit, was $59 \mathrm{mmol} / \mathrm{mol}$ or $7.6 \%$ (range $32-80 \mathrm{mmol} / \mathrm{mol}$ or 5.1-9.5\%).

Of the 77 observed parents (96\% mothers), 70 parents (96\% mothers) completed the questionnaire about general parenting stress and DSQoL of their child, 68 parents (96\% mothers) completed the questionnaire about the generic QoL of their child and 64 parents ( $94 \%$ mothers) completed the questionnaire about disease-related parenting stress. Most of the 70 parents (96\% mothers) who completed the questionnaires were cohabiting or married/registered partners ( $7 \%$ of the mothers and $0 \%$ of the fathers were single). More than half of the participating mothers (54\%) had a higher educational level (i.e. approximately 12 years of formal education), while all fathers $(100 \%)$ had a Bachelor's or Master's degree (i.e. approximately 15 years of formal education).

Table 1 (Socio)demographic and clinical characteristics of young children with type 1 diabetes and their parents

\begin{tabular}{|c|c|c|c|c|c|c|}
\hline & & & Number $(\%)$ & Median (percentile 25-75) & $\mathrm{M}$ & SD \\
\hline \multirow[t]{8}{*}{ Children } & Sex & $\begin{array}{l}\text { Boys } \\
\text { Girls }\end{array}$ & $\begin{array}{l}41(53 \%) \\
36(47 \%)\end{array}$ & & & \\
\hline & Age (years) & (range 2-7) & & $5(4-6)$ & & \\
\hline & $\mathrm{HbA}_{1 \mathrm{c}}$ & (range $32 \mathrm{mmol} / \mathrm{mol}-80 \mathrm{mmol} / \mathrm{mol}$ ) & 77 & & 59 & 9.03 \\
\hline & & (range $5.1 \%-9.5 \%$ ) & 77 & & $7.6 \%$ & $0.8 \%$ \\
\hline & Treatment & $\begin{array}{l}\text { Insulin pump } \\
\text { Multiple daily insulin injections }\end{array}$ & $\begin{array}{l}63(82 \%) \\
14(18 \%)\end{array}$ & & & \\
\hline & Blood glucose monitoring & Times a day (range 2-20) & & $6(5-7)$ & & \\
\hline & Years since diagnose & (range $1-6$ years) & & $2(1-3)$ & & \\
\hline & & & $\mathrm{N}$ (number $\mathrm{p}$ & total) & & \\
\hline \multirow[t]{16}{*}{ Parents } & Total & Mothers observed & $74(74 / 77)$ & & & \\
\hline & & Fathers observed & $3(3 / 77)$ & & & \\
\hline & Marital status (mothers) & $\begin{array}{l}\text { Single } \\
\text { Cohabiting }\end{array}$ & $\begin{array}{l}5(5 / 74) \\
10(10 / 74)\end{array}$ & & & \\
\hline & & Married / registered partners & $52(52 / 74)$ & & & \\
\hline & & Missing & $7(7 / 74)$ & & & \\
\hline & Marital status (fathers) & $\begin{array}{l}\text { Single } \\
\text { Cohabiting }\end{array}$ & $\begin{array}{l}0(0 / 3) \\
1(1 / 3)\end{array}$ & & & \\
\hline & & Married / registered partners & $2(2 / 3)$ & & & \\
\hline & & Missing & $0(0 / 3)$ & & & \\
\hline & Educational level (mothers) & $\begin{array}{l}\text { Primary education } \\
\text { About } 12 \text { years of formal education }\end{array}$ & $\begin{array}{l}1(1 / 74) \\
36(36 / 74)\end{array}$ & & & \\
\hline & & 15-16 years of formal education & $29(29 / 74)$ & & & \\
\hline & & Other & $1(1 / 74)$ & & & \\
\hline & & Missing & $7(7 / 74)$ & & & \\
\hline & Educational level (fathers) & $\begin{array}{l}\text { Primary education } \\
\text { About } 12 \text { years of formal education }\end{array}$ & $\begin{array}{l}0(0 / 3) \\
0(0 / 3)\end{array}$ & & & \\
\hline & & $15-16$ years of formal education & $3(3 / 3)$ & & & \\
\hline & & Other & $0(0 / 3)$ & & & \\
\hline & & Missing & $0(0 / 3)$ & & & \\
\hline
\end{tabular}




\section{Inter-rater reliability of the observations}

To assess the inter-rater reliability of the OKI-DO observations, a second observer (HvB) scored $20 \%$ of the videotapes independently of the first observer (AN). The agreement with the first observer was high as weighted kappa was 0.73 , indicating a good inter-rater reliability.

\section{Associations between parenting stress and the quality of parent-child interaction with $\mathrm{HbA}_{1 \mathrm{c}}$ levels and (diabetes-specific) quality of life}

Table 2 summarizes the Pearson correlations between general parenting stress, disease-related parenting stress and the domains of the quality of parent-child interaction with the $\mathrm{HbA}_{1 \mathrm{c}}$ level and (DS)QoL of the children.

Results showed that general and disease-related parenting stress were significantly negatively associated with both generic QoL (correlations ranging from -0.40 to -0.56 , medium to large effect sizes) and diabetes-specific QoL (correlations ranging from -0.39 to -0.70 , medium to large effect sizes). $\mathrm{HbA}_{1 \mathrm{c}}$ level did not correlate significantly with general or disease-related parenting stress. These results indicate that elevated levels of both general and disease-related parenting stress were associated with lower (DS)QoL of young children with T1DM.

Furthermore, only the OKI-DO domains emotional involvement ( $r=0.23$, small effect size) and child's response to injection ( $r=0.23$, small effect size) were significantly positively associated with the $\mathrm{Hba}_{1 \mathrm{c}}$ level of the child, which indicates that parents with children with higher $\mathrm{HbA}_{1 \mathrm{c}}$ levels were more emotionally involved and that children with higher $\mathrm{HbA}_{1 \mathrm{c}}$ levels expressed more discomfort during glucose monitoring (for example, more tension in body, tightening eyes, crying or resisting behavior). A better quality of instruction was associated with a better generic QoL in children aged 6-7 ( $r=0.41$, medium effect size), and more emphasis on diabetes during the meal was significantly correlated with a better DSQoL in children aged 0-5 ( $r=0.36$, medium effect size).

\section{Discussion}

For health-care providers, maintaining or enhancing a good QoL of children with T1DM is as important as guarding or achieving good glycemic control [13]. However, research examining factors that are associated with $\mathrm{HbA}_{1 \mathrm{c}}$ levels and (DS)QoL in young children with T1DM is still scarce. The present study focused on this youngest patient group and found that higher levels of (disease-related) parenting stress were associated with a lower (DS)QoL of the child and that emotional involvement and the child's response to injection were associated with lower $\mathrm{HbA}_{1 \mathrm{c}}$ levels.

The results showed that parenting stress was not associated with $\mathrm{HbA}_{1 \mathrm{c}}$ levels. A previous study, however, concluded that higher levels of disease-related parenting stress were

Table 2 Relationships between (disease-related) parenting stress, the OKI-DO domains and child (health) outcomes

\begin{tabular}{|c|c|c|c|c|c|c|c|}
\hline & \multirow{3}{*}{$\begin{array}{l}\mathrm{HbA}_{1 \mathrm{c}} \\
r\end{array}$} & \multicolumn{3}{|l|}{$0-5$ years } & \multicolumn{3}{|l|}{ 6-7 years } \\
\hline & & \multicolumn{2}{|l|}{ Generic QoL } & \multirow{2}{*}{$\begin{array}{l}\text { DSQoL } \\
\text { Total } \\
r\end{array}$} & \multicolumn{2}{|l|}{ Generic QoL } & \multirow{2}{*}{$\begin{array}{l}\text { DSQoL } \\
\text { Total } \\
r\end{array}$} \\
\hline & & $\begin{array}{l}\text { Health related } \\
r\end{array}$ & $\begin{array}{l}\text { Psycho-social } \\
r\end{array}$ & & $\begin{array}{l}\text { Health related } \\
r\end{array}$ & $\begin{array}{l}\text { Psycho-social } \\
r\end{array}$ & \\
\hline \multicolumn{8}{|l|}{ Parenting stress } \\
\hline General total & 0.12 & -0.13 & -0.18 & $-0.42 * *$ & $-0.53 * *$ & $-0.56^{* *}$ & $-0.70 * *$ \\
\hline Disease-related frequency total & -0.15 & -0.19 & -0.18 & $-0.39^{*}$ & $-0.56^{* *}$ & $-0.40^{*}$ & $-0.69 * *$ \\
\hline Disease-related difficulty total & -0.09 & -0.16 & -0.10 & -0.33 & $-0.52^{*}$ & -0.27 & $-0.70 * *$ \\
\hline \multicolumn{8}{|l|}{ Parent-child interaction } \\
\hline Emotional involvement & $0.23 *$ & -0.12 & 0.13 & -0.04 & 0.02 & -0.01 & 0.25 \\
\hline Limit setting & 0.08 & -0.17 & 0.07 & 0.03 & -0.13 & -0.12 & 0.02 \\
\hline Respect for autonomy & -0.05 & -0.17 & -0.11 & -0.22 & 0.08 & 0.19 & 0.23 \\
\hline Quality of instruction & -0.12 & -0.16 & -0.08 & 0.02 & 0.13 & $0.41^{*}$ & 0.19 \\
\hline Negative behavior & 0.03 & 0.20 & 0.08 & 0.26 & 0.35 & 0.22 & 0.15 \\
\hline Avoidance & -0.02 & 0.15 & 0.16 & 0.08 & -0.06 & -0.30 & -0.16 \\
\hline Cooperative behavior & 0.11 & -0.12 & 0.03 & -0.02 & 0.18 & -0.05 & 0.16 \\
\hline Child's response to injection & $0.23 *$ & -0.16 & -0.01 & -0.14 & 0.03 & -0.32 & -0.13 \\
\hline Emphasis on diabetes & 0.14 & 0.07 & 0.22 & $0.36^{*}$ & 0.24 & 0.08 & -0.10 \\
\hline Mealtime structure & -0.02 & -0.19 & -0.10 & -0.11 & -0.25 & -0.19 & -0.07 \\
\hline
\end{tabular}

$*_{p}<.05 ; * * p<.01$ 
associated with more optimal $\mathrm{HbA}_{1 \mathrm{c}}$ levels in young children with T1DM [7]. An explanation of the discrepancy in findings between our study (no significant correlation) and the study of Stallwood [43] might be explained by type of insulin treatment: parents generally experience less disease-related parenting stress when their child is on insulin pump therapy [29,45]. In the study of Stallwood [43], none of the children used pump therapy, in contrast to $84 \%$ of the children in the present study. Future research should examine the association between glycemic control and disease-related parenting stress in a sample with a comparable amount of children using multiple daily insulin injections versus insulin pump therapy to see whether there is or is not a significant association between diseaserelated parenting stress and $\mathrm{HbA}_{1 \mathrm{c}}$ levels. If there indeed is a significant association, appropriate interventions in order to lower disease-related parenting stress could be part of the treatment in lowering $\mathrm{HbA}_{1 \mathrm{c}}$ levels.

Furthermore, parents who experienced higher levels of (disease-related) parenting stress reported lower child QoL, especially DSQoL (e.g. problems with insulin administration, glucose monitoring, energy level, health, etc.). This is in line with a study examining the associations between parenting stress and the QoL of teenagers with T1DM [60], but the present study is the first study that has examined this relationship in young children with T1DM. Because of these results, health-care providers should not only be aware of the (DS)QoL of the child, but also the perceived (diseaserelated) parenting stress of the parents as higher levels of (disease-related) parenting stress are associated with lower (DS)QoL. Therefore, health-care providers should monitor the level of (disease-related) parenting stress regularly in order to avoid a low QoL of the child.

Parents were more emotionally involved when their child had a suboptimal $\mathrm{HbA}_{1 \mathrm{c}}$ level. Research with older children and adolescents with T1DM also showed that a suboptimal $\mathrm{HbA}_{1 \mathrm{c}}$ level was positively associated with emotional involvement of the parents [26] and involvement in diabetes care [6]. However, the causal direction of this association remains unclear. It could be that parents are more emotionally involved when trying to get a more optimal $\mathrm{HbA}_{1 \mathrm{c}}$ level and thereby delaying the onset of long- and short-term complications [26]. Otherwise, it could also be true that parents who are highly emotionally involved during diabetes-specific situations deliberately set higher $\mathrm{HbA}_{1 \mathrm{c}}$ targets for their child because of fear of hypoglycemia [36].

Furthermore, the results showed that children with a high $\mathrm{HbA}_{1 \mathrm{c}}$ level expressed more discomfort during glucose monitoring and/or insulin administration (for example, more tension in body, tightening eyes, crying or resisting). Displaying more discomfort could be due to some form of needle phobia or a low pain threshold. When children experience needle phobia or have a low pain threshold, parents might postpone or omit insulin injections or glucose monitoring in order to avoid these stressful and unpleasant situations, which could result in suboptimal $\mathrm{HbA}_{1 \mathrm{c}}$ levels [20]. It could also be true that a high $\mathrm{HbA}_{1 \mathrm{c}}$ level might 'worsen' the diabetes for both parent and child, and that the child, due to an emphasis on their disease, experiences more discomfort during glucose monitoring and/or insulin administration.

Remarkably, the other domains of parent-child interaction around the diabetes situation were not related to $\mathrm{HbA}_{1 \mathrm{c}}$ level. Based on results of a previous study with young children [37] and studies with older children [2, 6, 10, 22, 26, 27, 59], showing that ineffective parenting strategies and child misbehavior were significantly correlated with less optimal $\mathrm{HbA}_{1 \mathrm{c}}$ levels, we expected that, for example, less respect for autonomy or more negative behavior of the child would be associated with suboptimal $\mathrm{HbA}_{1 \mathrm{c}}$ levels. This discrepancy in findings might be due to different sample characteristics, as our sample had more optimal $\mathrm{HbA}_{1 \mathrm{c}}$ levels $(7.6 \%$ or about $59 \mathrm{mmol} / \mathrm{mol}$ in our study versus $>8 \%$ or $>64 \mathrm{mmol} / \mathrm{mol}[2$, $6,10,26,37])$. Furthermore, the children in our sample were much younger than in most other studies $[2,6,10,22,26,27$, 59]. Also, it is possible that families who encountered problems (like child misbehavior) during the mealtime situation (including glucose monitoring and insulin administration) were reluctant to participate in the present study. Our sample consisted of rather high-functioning families, meaning that they did not encounter major problems during mealtime, glucose monitoring and insulin administration [33].

The quality of parent-child interaction did not show clear patterns of correlations with (DS)QoL. Previous research with youth with T1DM showed that parent-child behaviors (e.g. diabetes-specific family conflict, warmth) were related to QoL $[18,24]$. The parent-child behaviors in these studies were collected through self-report questionnaires $[18,24]$. Weisberg-Benchell [56] also examined the relationship between QoL and parent-child behavior, but they used both self-report questionnaires and observations to assess parentchild behaviors. While the self-reported parent-child behaviors did correlate with QoL, the observed parent-child behaviors did not [56]. This highlights the importance of using direct observations in examining the quality of parent-child interaction in future studies, with an observational instrument like the OKI-DO instrument, as self-reports might reflect a more subjective view.

The present study has some limitations that need to be described. Research has shown that diabetes centers not only differ in structural issues, but also at an educational level and guidance regarding diabetes, which could influence glycemic control [11]. Because we included children from 15 different hospitals/institutions, the diabetes education and guidance these parents and children receive(d) could be very different. Furthermore, our sample consisted of almost only Caucasian participants $(97 \%)$. Participation rate among fathers was very low, and most of the parents had a relatively high educational 
level, which is not a fair representation of the population in the Netherlands [51]. As the educational level and socioeconomic status of parents are positively associated with the quality of parent-child interaction [47] and parenting strategies [5, 39], the results of the present study may not be generalized to parents with a lower educational level. Also, because of the videotaped home visits, it is possible that families who frequently experience problems during mealtime, glucose monitoring and/or insulin administration were reluctant to participate in our study, which might have led to biased results. Future research, therefore, should examine whether a causal relationship exists between the quality of the parent-child interaction and (diseaserelated) parenting stress with (health) outcomes of children with T1DM, including families of different ethnic backgrounds, parents with lower educational levels and families who encounter problems during diabetesspecific situations.

A strength of the present study is the use of the OKIDO instrument, as observations of "real-life" parentchild interactions and scored by an independent observer can provide more objective data to assess the quality of parent-child interaction than using self-report questionnaires or interviews [33]. The OKI-DO instrument could be used by health-care providers to evaluate interventions (like video interaction guidance) aimed at optimizing the quality of parent-child interaction and/or lowering the parenting stress in order the influence child outcomes. Furthermore, as recommended by Nakagawa [30], we refrained from correcting for examining multiple associations to be able to give an overview of all the associations that were examined as we were interested in all possible associations between the included variables. Another strength is the support from several large diabetes clinics in the Netherlands. Therefore, it was possible to focus on younger children with T1DM and their families, which makes this study innovative as this patient group is understudied.

The results of the present paper support the notion that diabetes does not only affect the child with T1DM: T1DM is a family disease, as parenting factors (like stress and parentchild interactions) are associated with important child outcomes. Therefore, it is important for health-care providers to not only focus on the child with T1DM, but also on the family system.

Acknowledgments We would like to thank all families, hospitals/ institutions (St. Elisabeth Hospital Tilburg, TweeSteden Hospital Tilburg, Catharina Hospital Eindhoven, St. Anna Hospital Geldrop, Bernhoven Hospital Uden, Jeroen Bosch Hospital Den Bosch, Elkerliek Hospital Helmond, Diabeter Rotterdam, Isala Clinics Zwolle, Amphia Hospital Breda, Franciscus Hospital Roosendaal, Academic Hospital Maastricht, Medical Spectrum Twente Enschede, Zorg Groep Twente Almelo/
Hengelo, Atrium Medical Center Heerlen) and their pediatricians/ diabetes nurses for their time and hospitality to participate in this study.

Authors' contributions This study was developed by EH, FP and HvB, they participated in the concept, design and interpretation of the manuscript. HJA and EvM are the studycoordinators of participating centers and coordinated the inclusion. WE conceptualized and advised on the analysis. AN designed the OKI-DO instrument, collected and interpreted the data, and coordinated the draft of the manuscript. All the listed authors have reviewed and approved the final version of the manuscript as submitted.

Conflict of interest The authors declare that they have no conflict of interest.

Ethical standards The study was approved by the Medical Ethical Review board of St. Elisabeth Hospital Tilburg (date: 25-05-2010). All parents gave their consent prior to their inclusion in the study.

Open Access This article is distributed under the terms of the Creative Commons Attribution 4.0 International License (http://creativecommons.org/licenses/by/4.0/), which permits unrestricted use, distribution, and reproduction in any medium, provided you give appropriate credit to the original author(s) and the source, provide a link to the Creative Commons license, and indicate if changes were made.

\section{References}

1. Abidin RR (1990) Parenting stress index/short form manual. Western Psychological Services, Los Angeles

2. Anderson BJ, Vangsness L, Connell A, Butler D, Goebel-Fabbri A, Laffel LM (2002) Family conflict, adherence, and glycaemic control in youth with short duration Type 1 diabetes. Diabet Med 19: 635-642

3. Barat P, Valade A, Brosselin P, Alberti C, Maurice-Tison S, LevyMarchal C (2008) The growing incidence of type 1 diabetes in children: the 17-year French experience in Aquitaine. Diabetes Metab 34:601-605

4. Belsky J (1984) The determinants of parenting: a process model. Child Dev 55:83-96

5. Bradley RH, Corwyn RF (2002) Socioeconomic status and child development. Annu Rev Psychol 53:371-399

6. Cameron FJ, Skinner TC, de Beaufort CE, Hoey H, Swift PG, Aanstoot H, Aman J, Martul P, Chiarelli F, Daneman D, Danne T, Dorchy H, Kaprio EA, Kaufman F, Kocova M, Mortensen HB, Njolstad PF, Phillip M, Robertson KJ, Schoenle EJ, Urakami T, Vanelli M, Ackermann RW, Skovlund SE, Hvidoere Study Group on Childhood Diabetes (2008) Are family factors universally related to metabolic outcomes in adolescents with Type 1 diabetes? Diabet Med 25:463-468

7. Cohen B (1988) Statistical power analysis for the behavioral sciences. Lawrence Erlbaum, Hillsdale, New Jersey

8. Cousino MK, Hazen RA (2013) Parenting stress among caregivers of children with chronic illness: a systematic review. J Pediatr Psychol 38:809-828

9. Dahlquist G, Kallen B, Swedish Childhood Diabetes Study Group (2007) School performance in children with type 1 diabetes - a population-based register study. Diabetologia 50:957-964

10. Davis CL, Delamater AM, Shaw KH, La Greca AM, Eidson MS, Perez-Rodriguez JE, Nemery R (2001) Brief report: Parenting styles, regimen adherence, and glycemic control in 4-to 10-yearold children with diabetes. J Pediatr Psychol 26:123-129

11. de Beaufort CE, Swift PG, Skinner CT, Aanstoot HJ, Aman J, Cameron F, Martul P, Chiarelli F, Daneman D, Danne T, Dorchy 
H, Hoey H, Kaprio EA, Kaufman F, Kocova M, Mortensen HB, Njolstad PR, Phillip M, Robertson KJ, Schoenle EJ, Urakami T, Vanelli M, Hvidoere Study Group on Childhood Diabetes 2005 (2007) Continuing stability of center differences in pediatric diabetes care: do advances in diabetes treatment improve outcome? The Hvidoere Study Group on Childhood Diabetes. Diabetes Care 30: 2245-2250

12. de Brock A, Vermulst AA, Gerris JRM, Veerman JW, Abidin RR (2004) NOSIK: Nijmeegse Ouderlijke Stress Index, 17-item version. Praktikon, Nijmegen

13. Editorial (1995) Quality of life and clinical trials. Lancet 1:346

14. Emmanouilidou E, Galli-Tsinopoulou A, Karavatos A, NousiaArvanitakis S (2008) Quality of life of children and adolescents with diabetes of Northern Greek origin. Hippokratia 12:168-175

15. Fekkes M, Bruil J, Vogels T (2004) TAPQOL-manual. Developed by Leiden Center for Child Health and Pediatrics LUMC-TNO

16. Fekkes M, Theunissen NCM, Brusman E, Veen S, Verrips EGH, Koopman HM, Vogels T, Wit JM, Verloove-Vanhorick SP (2000) Development and psychometric evaluation of the TAPQOL: a health-related quality of life instrument for 1-5-year-old children. Qual Life Res 9:961-972

17. Gerstl EM, Rabl W, Rosenbauer J, Gröbe H, Hofer SE, Krause U, Holl RW (2008) Metabolic control as reflected by HbAlc in children, adolescents and young adults with type 1 diabetes mellitus: combined longitudinal analysis including 27,035 patients from 207 centers in Germany and Austria during the last decade. Eur J Pediatr 167:447-453

18. Grey M, Boland EA, Yu C, Sullivan-Bolyai S, Tamborlane WV (1998) Personal and family factors associated with quality of life in adolescents with diabetes. Diabetes Care 21:909-914

19. Grootenhuis MA, Koopman HM, Verrips EG, Vogels AG, Last BF (2007) Health-related quality of life problems of children aged 8-11 years with a chronic disease. Dev Neurorehabil 10:27-33

20. Hanas R, Ludvigsson J (1997) Experience of pain from insulin injections and needle-phobia in young patients with IDDM. Practical Diabetes Int 14:95-99

21. Hoey H, Lange K, de Beaufort C, Aanstoot HJ, Aman J, Barrett T, Cameron F, Castano L, Chiarelli F, Danne T, Dorchy H, Fischer L, Jarosz-Chobot P, Kaprio E, Kocova M, Mortensen H, Neu A, Njolstad P, Palmert M, Philip M, Robert JJ, Robertson K, Schonle E, Skovlund S, Swift P, Urakami R, Hvidoere Study Group (2011) Quality of life in 1043 young children with diabetes: a new smiley faces international qol assessment tool. Pediatr Diabetes 12(Supplement 15):88-89

22. Jaser SS, Grey M (2010) A pilot study of observed parenting and adjustment in adolescents with type 1 diabetes and their mothers. J Pediatr Psychol 35:738-747

23. Kalyva E, Malakonaki E, Eiser C, Mamoulakis D (2011) Healthrelated quality of life (HRQoL) of children with type 1 diabetes mellitus (T1DM): self and parental perceptions. Pediatr Diabetes 12:34-40

24. Laffel LM, Connell A, Vangsness L, Goebel-Fabbri A, Mansfield A, Anderson BJ (2003) General quality of life in youth with type 1 diabetes: relationship to patient management and diabetes-specific family conflict. Diabetes Care 26:3067-3073

25. Leonard BJ, Jang YP, Savik K, Plumbo PM, Christensen R (2002) Psychosocial factors associated with levels of metabolic control in youth with type 1 diabetes. J Pediatr Nurs 17:28-37

26. Liakopoulou M, Alifieraki T, Katideniou A, Peppa M, Maniati M, Tzikas D, Hibbs ED, Dacou-Voutetakis C (2001) Maternal expressed emotion and metabolic control of children and adolescents with diabetes mellitus. Psychother Psychosom 70:78-85

27. Martin MT, Miller-Johnson S, Kitzmann KM, Emery RE (1998) Parent-child relationships and insulin-dependent diabetes mellitus: Observational ratings of clinically relevant dimensions. J Fam Psychol 12:102-111
28. McDonnell CM, Northam EA, Donath SM, Werther GA, Cameron FJ (2007) Hyperglycemia and externalizing behavior in children with type 1 diabetes. Diabetes Care 30:2211-2215

29. Müller-Godeffroy E, Treichel S, Wagner VM (2009) Investigation of quality of life and family burden issues during insulin pump therapy in children with Type 1 diabetes mellitus-a large-scale multicentre pilot study. Diabet Med 26:493-501

30. Nakagawa S (2004) A farewell to Bonferroni: the problems of low statistical power and publication bias. Behav Ecol 15:1044-1045

31. Nakamura N, Sasaki N, Kida K, Matsuura N (2010) Health-related and diabetes-related quality of life in Japanese children and adolescents with type 1 and type 2 diabetes. Pediatr Int 52:224-229

32. Nieuwesteeg A, Pouwer F, van der Kamp R, van Bakel H, Aanstoot HJ, Hartman E (2012) Quality of life of children with type 1 diabetes: a systematic review. Curr Diabetes Rev 8:434-443

33. Nieuwesteeg A, Hartman E, Pouwer F, Emons W, Aanstoot H-J, van Mil E, van Bakel H (2014) Qualitative observation instrument to measure the quality of parent-child interactions in young children with type 1 diabetes mellitus. BMC Pediatr 14:145

34. Ostberg M, Hagekull B (2000) A structural modeling approach to the understanding of parenting stress. J Clin Child Psychol 29:615625

35. Patterson CC, Dahlquist GG, Gyürüs E, Green A, Soltész G, EURODIAB Study Group (2009) Incidence trends for childhood type 1 diabetes in Europe during 1989-2003 and predicted new cases 2005-20: a multicentre prospective registration study. Lancet 373:2027-2033

36. Patton SR, Dolan LM, Henry R, Powers SW (2007) Parental fear of hypoglycemia: young children treated with continuous subcutaneous insulin infusion. Pediatr Diabetes 8:362-368

37. Patton SR, Dolan LM, Powers SW (2006) Mealtime interactions relate to dietary adherence and glycemic control in young children with type 1 diabetes. Diabetes Care 29:1002-1006

38. Persson S, Dahlquist G, Gerdtham UG, Steen Carlsson K (2013) Impact of childhood-onset type 1 diabetes on schooling: a population-based register study. Diabetologia 56:1254-1262

39. Pinderhughes EE, Dodge KA, Bates JE, Pettit GS, Zelli A (2000) Discipline responses: influences of parents' socioeconomic status, ethnicity, beliefs about parenting, stress, and cognitive-emotional processes. J Fam Psychol 14:380-400

40. Rewers M, Pihoker C, Donaghue K, Hanas R, Swift P, Klingensmith GJ (2009) Assessment and monitoring of glycemic control in children and adolescents with diabetes. ISPAD clinical practice consensus guidelines 2009 compendium. Pediatr Diabetes 10:71-81

41. Rosenbauer J, Dost A, Karges B, Hungele A, Stahl A, Bachle C, Gerstl EM, Kastendieck C, Hofer SE, Holl RW (2012) Improved metabolic control in children and adolescents with type 1 diabetes: a trend analysis using prospective multicenter data from Germany and Austria. Diabetes Care 35:80-86

42. Sherifali D, Ciliska D, O'Mara L (2009) Parenting children with diabetes: exploring parenting styles on children living with type 1 diabetes mellitus. Diabetes Educ 35:476-483

43. Stallwood L (2005) Influence of caregiver stress and coping on glycemic control of young children with diabetes. J Pediatr Health Care 19:293-300

44. Streisand R, Braniecki S, Tercyak KP, Kazak AE (2001) Childhood illness-related parenting stress: the pediatric inventory for parents. J Pediatr Psychol 26:155-162

45. Streisand R, Swift E, Wickmark T, Chen R, Holmes CS (2005) Pediatric parenting stress among parents of children with type 1 diabetes: the role of self-efficacy, responsibility, and fear. J Pediatr Psychol 30:513-521

46. The Diabetes Control and Complications Trial Research Group (1993) The effect of intensive treatment of diabetes on the 
development and progression of long-term complications in insulin-dependent diabetes mellitus. N Engl J Med 329:977-986

47. van Bakel HJ, Riksen-Walraven JM (2002) Parenting and development of one-year-olds: links with parental, contextual, and child characteristics. Child Dev 73:256-273

48. van Dam C, Nijhof K, Scholte R, Veerman JW (2010) Nieuw zorgaanbod - gesloten jeugdzorg voor jongeren met ernstige gedragsproblemen - eindrapport. Praktikon, Nijmegen

49. Varni JW, Burwinkle TM, Jacobs JR, Gottschalk M, Kaufman F, Jones KL (2003) The PedsQL in type 1 and type 2 diabetes: reliability and validity of the Pediatric Quality of Life Inventory Generic Core Scales and type 1 Diabetes Module. Diabetes Care 26:631-637

50. Vehik K, Hamman FR, Lezote D, Norris JM, Klingensmith G, Bloch C, Rewers M, Dabelea D (2007) Increasing incidence of type 1 diabetes in 0- to 17-year-old Colorado youth. Diabetes Care 30: 503-509

51. Verweij A, Sanderse C, vd Lucht F (2010) Wat is de huidige situatie? In: Volksgezondheid Toekomst Verkenning, Nationaal Kompas Volksgezondheid. RIVM, Bilthoven

52. Vogels T, Verrips GHW, Koopman HM, Theunissen NCM, Fekkes M, Kamphuis RP (2000) TACQOL manual parent and child form. Leiden Center for child health and pediatrics LUMC-TNO

53. Vollrath ME, Landolt MA, Gnehm HE, Laimbacher J, Sennhauser FH (2007) Child and parental personality are associated with glycaemic control in Type 1 diabetes. Diabet Med 24:1028-1033

54. Vrijmoet-Wiersma CM, Hoekstra-Weebers JE, Margreet de Peinder WM, Koopman HM, Tissing WJ, Treffers PD, Bierings MB, Jansen NC, Grootenhuis MA, Egeler RM (2010) Psychometric qualities of the Dutch version of the Pediatric Inventory for Parents (PIP): a multi-center study. Psychooncology 19:368-375

55. Weissberg-Benchell J, Glasgow A (1997) The role of temperament in children with insulin-dependent diabetes mellitus. J Pediatr Psychol 22:795-809

56. Weissberg-Benchell J, Nansel T, Holmbeck G, Chen R, Anderson B, Wysocki T, Laffel L (2009) Generic and diabetes-specific parent-child behaviors and quality of life among youth with type 1 diabetes. J Pediatr Psychol 34:977-988

57. Whittemore R, Jaser S, Chao A, Jang M, Grey M (2012) Psychological experience of parents of children with type 1 diabetes: a systematic mixed-studies review. Diabetes Educ 38:562-579

58. Wilson S, Durbin CE (2012) Dyadic parent-child interaction during early childhood: contributions of parental and child personality traits. J Pers 80:1313-1338

59. Worrall-Davies A, Owens D, Holland P, Haigh D (2002) The effect of parental expressed emotion on glycaemic control in children with Type 1 diabetes. Parental expressed emotion and glycaemic control in children. J Psychosom Res 52:107-113

60. Wu YP, Grave MM, Roberts MC, Mitchell AC (2010) Is insulin pump therapy better than injection for adolescents with diabetes? Diabetes Res Clin Pract 89:121-125

61. Wysocki T, Huxtable K, Linscheid TR, Wayne W (1989) Adjustment to diabetes mellitus in preschoolers and their mothers. Diabetes Care 12:524-529

62. Wysocki T, Harris MA, Buckloh LM, Mertlich D, Lochrie AS, Taylor A, Sadler M, White NH (2008) Randomized, controlled trial of Behavioral Family Systems Therapy for Diabetes: maintenance and generalization of effects on parent-adolescent communication. Behav Ther 39:33-46 